Special issue of the 2nd International Conference on Computational and Experimental Science and Engineering (ICCESEN 2015)

\title{
Numerical Simulation of Temperature Distribution Field in Beam Bulk in the Simultaneous Presence of Heat Insulation, Heat Flux and Heat Exchange
}

\author{
A. KudAYKULOV ${ }^{a}$ AND A. Zhumadillayeva ${ }^{b, *}$ \\ ${ }^{a}$ Institute of Information and Computer Technologies, Almaty, Kazakhstan \\ ${ }^{b}$ L.N.Gumılyov Eurasian National University, Astana, Kazakhstan
}

\begin{abstract}
In the work at the level of basic laws of conservation of energy combined with the use of quadratic spline functions a resolving system of equations is constructed. Herewith, the procedure is prepared to minimize the functionals of total thermal energy and potential energy of elastic deformation involving temperature field.
\end{abstract}

DOI: 10.12693/APhysPolA.130.335

PACS/topics: 45.20.dh, 44.05.+e

\section{Introduction}

Most of the bearing elements of electric power installations operate in the presence of local cold insulator, heat flow, and heat transfer. To ensure the smooth operation of these elements it is necessary to develop appropriate computational algorithms and methods that allow to investigate numerically the thermomechanical condition of bearing elements. Besides, obtained numerical results should have different precision and respectively describe such a complex exceptional nonlinear process under study.

Under the established process for the length of the test rod bearing element temperature field, displacement field, elastic, thermal and thermoelastic stress components field will arise. To determine these decisions, taking into account natural conditions and maintenance, we should use the techniques oriented on the basic laws of conservation of energy $[1,2]$.

\section{Formulation of the problem and methods}

We consider the bearing member in the form of a horizontal rod of bounded length $L(\mathrm{~cm})$ and constant crosssection $F\left(\mathrm{~cm}^{2}\right)$, the thermal conductivity of the rod material $K_{x x}(\mathrm{~W} / \mathrm{cm} \mathrm{K})$, the linear expansion $\alpha(1 / \mathrm{K})$, the elastic module $E\left(\mathrm{kG} / \mathrm{cm}^{2}\right)$. Both ends of the rod tightly clamped.

We sway coordinate axis $O X$ from the left to the right. It coincides with the axis of the rod. At the closed side surface of the rod heat current $q(x),\left(\mathrm{W} / \mathrm{cm}^{2}\right)=\mathrm{ax}+\mathrm{b}$, $0 \leq x \leq L$ is brought, which varies linearly along the length of the rod. Through the cross-sectional area the heat transfer with the environment occurs. Herewith, the heat transfer cooficient is $h\left(\mathrm{~W} / \mathrm{cm}^{2} \mathrm{~K}\right)$ and the environment temperature is $T_{\mathrm{TE}}$. To determine the temperature

\footnotetext{
* corresponding author; e-mail: ay8222@mail.ru
}

field along the length of the rod a functionality of full thermal energy is constructed [1, 2].

A limited length of the rod is given $L(\mathrm{~cm})$, both ends of which is fixed hard, the area of the cross-sectional rod $F\left(\mathrm{~cm}^{2}\right)$ is constant along the length of the rod. Physical and mechanical and thermal properties of the rod material is characterized by an elastic modulus $E\left(\mathrm{kG} / \mathrm{cm}^{2}\right)$, the coefficient of heat expansion $\alpha(1 / \mathrm{K})$, heat conduction $K_{x x}(\mathrm{~W} / \mathrm{cm} \mathrm{K})$ and the coefficient of heat transfer with the environment $h\left(\mathrm{~W} / \mathrm{cm}^{2} \mathrm{~K}\right)$. Heat current on the entire length of the side surface of the rod is supplied, which changes along with the length of the rod, following a linear manner:

$$
\begin{aligned}
J & =\int_{F(x)=0} \frac{h}{2}\left(T-T_{\mathrm{TE}}\right)^{2} \mathrm{~d} S+\int_{S_{\mathrm{als}}} q T \mathrm{~d} S \\
& +\int_{F(x)=L} \frac{h}{2}\left(T-T_{\mathrm{TE}}\right)^{2} \mathrm{~d} S+\int_{V} \frac{K_{x x}}{2}\left(\frac{\partial T}{\partial x}\right)^{2} \mathrm{~d} V .(1)
\end{aligned}
$$

$S_{\text {als }}$ is the area of the lateral surface of the rod. Minimizing this functional on discrete nodal values of the temperature a resolving system of linear algebraic equations with account for natural boundary conditions is constructed

$$
\frac{\partial J}{\partial T_{i}}=0, \quad i=1, \ldots, 2 n+1 .
$$

$n$ is the number of discrete elements. Within the length of each discrete element temperature field is approximated by quadratic spline functions $[3,4]$.

After determining the temperature field a functional of potential energy of the elastic deformation with account for the presence of the temperature field is formed [5]:

$$
\Pi=\int_{V} \frac{\sigma_{x}}{2} \varepsilon_{x} \mathrm{~d} V-\int_{V} \alpha E T(x) \varepsilon_{x} \mathrm{~d} V .
$$

$\varepsilon_{x}$ is a component of the elastic longitudinal deformation, $u(x)(\mathrm{cm})$ is a displacement of points of the rod, and $\sigma_{x}$ is stress. Further, minimizing the last functional on nodal values a resolving system of linear equations based on the natural boundary conditions is formed 


$$
\frac{\partial \Pi}{\partial U_{i}}=0, \quad i=1, \ldots, 2 n+1 .
$$

Then a displacement field is formed, and on it a field of strain and stress is built.

\section{Numerical results}

To get the numerical results we use the following: $L=$ $30 \mathrm{~cm}$ - length of the rod, $E=2 \times 10^{6} \mathrm{kG} / \mathrm{cm}^{2}-$ a modulus elasticity of the rod material, $E=2 \times 10^{6} \mathrm{kG} / \mathrm{cm}^{2}$ - a coefficient of the thermal conductivity of rod material, and $\alpha=125 \times 10^{-7} 1 / \mathrm{K}$ - the coefficient of thermal expansion. $h=10 \mathrm{~W} / \mathrm{cm}^{2}$ - heat transfer coefficient, $T_{\mathrm{TE}}=40 \mathrm{~K}$ - the temperature of the environment. Heat current on the lateral surface of the rod is given by the following linear law. $n=100$ - the lengths of the discrete element.

With these initial data a field of stress components has the form shown in Fig. 1.

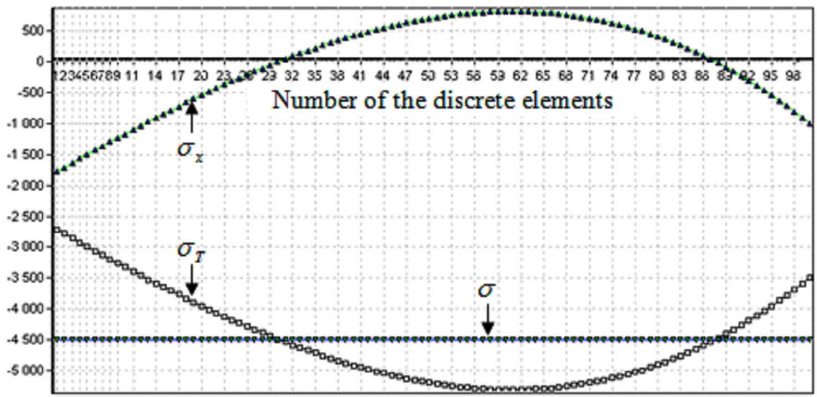

Fig. 1. Field of distribution $\varepsilon_{x}, \sigma_{x}, \sigma_{T}, \sigma$.

This shows that the elastic component of the strain $\sigma_{x}\left(\mathrm{~kg} / \mathrm{cm}^{2}\right)$ in discrete elements $1-31$ is compressed, 3288 is stretched, and 89-100 is compressed again, while the behavior of the temperature component of the strain $\sigma_{T}$ will be constricting along the entire length of the rod. It has the shape of a curve of higher order. Thermoelastic component of the strain $\sigma$ across the length of the rod is constant and has a contractive character.

TABLE I

Effect of the length of the rod on the thermal stress-strain deformed state of the test rod.

\begin{tabular}{c|c|c|c|c}
\hline \hline No. & $L[\mathrm{~cm}]$ & $R[\mathrm{kG}]$ & $\sigma\left[\mathrm{kG} / \mathrm{cm}^{2}\right]$ & {$[\%]$} \\
\hline 1. & 30 & -56454.58 & -4494.79 & 100 \\
2. & 27 & -47446.29 & -3769.61 & 83.86 \\
3. & 24 & -39522.13 & -3146.66 & 70 \\
4. & 21 & -32893.79 & -2618.93 & 58.26 \\
5. & 18 & -27272.95 & -2179.375 & 48.48 \\
6. & 15 & -22871.3 & -1820.96 & 40.5
\end{tabular}

Tables I-III shows the dependence of the occurring thermoelastic compressive force $R$ and strain $\sigma$ on the length of the rod $L$, the heat transfer coefficient $h$ and the environment temperature $T_{\mathrm{TE}}$.

These computational experiments shows that the decrease in length of the rod of environment temperature
TABLE II

Influence of the heat transfer coefficient on the thermal stress-strain deformed state of the test rod.

\begin{tabular}{c|c|c|c|c}
\hline \hline No. & $h\left[\mathrm{~W} / \mathrm{cm}^{2}\right]$ & $R[\mathrm{kG}]$ & $\sigma\left[\mathrm{kG} / \mathrm{cm}^{2}\right]$ & {$[\%]$} \\
\hline 1. & 10 & -56454.58 & -4494.79 & 100 \\
2. & 9 & -59332.916 & -4723.958 & 105.1 \\
3. & 8 & -62930.83 & -5010.41 & 111.47 \\
4. & 7 & -67556.72 & -5378.72 & 119.66 \\
5. & 6 & -73724.583 & -5869.79 & 130.59 \\
6. & 5 & -82359.583 & -6557.29 & 145.88
\end{tabular}

TABLE III

Effect of ambient temperature on the thermal stressstrain deformed state of the test rod.

\begin{tabular}{c|c|c|c|c}
\hline \hline No. & $T_{\mathrm{TE}}\left[{ }^{\circ} \mathrm{C}\right]$ & $R[\mathrm{kG}]$ & $\sigma\left[\mathrm{kG} / \mathrm{cm}^{2}\right]$ & {$[\%]$} \\
\hline 1. & 40 & -56454.58 & -4494.79 & 100 \\
2. & 35 & -54884.58 & -4369.79 & 97.22 \\
3. & 30 & -53314.58 & -4244.79 & 94.438 \\
4. & 25 & -51744.58 & -4119.79 & 91.657 \\
5. & 20 & -50174.58 & -3994.79 & 88.876
\end{tabular}

leads to a significant decrease in the resulting force values and strain. Reducing the coefficient of heat transfer leads to a significant increase in the values $R$ and $\sigma$.

\section{Conclusion}

A developed computational algorithm and numerical method allows to investigate the thermomechanical state of the bearing structural elements in the form of rods with high precision and in all operating conditions. Thus we can solve the class of steady problems of thermomechanical state of the rods under the influence of different types of local heat sources with the help of the proposed numerical method.

\section{Acknowledgments}

This work has been supported by Kazakhstan Ministry of Education via Research Grant Scheme.

\section{References}

[1] L.D. Landau, E.M. Lifshitz, Mechanics, Vol. 1 of A Course of Theoretical Physics, Pergamon Press, 1969.

[2] K. Amirtayev, A. Ibadullayeva, L. Naizabayeva, Z. Shermentayeva, in: Proc. Application of Information and Communication Technologies (AICT), 2014 IEEE 8th Int. Conf., Astana (Kazakhstan), IEEE, 2014, p. 115 .

[3] O.C. Zienkiewicz, R.L. Taylor, J.Z. Zhu, The Finite Element Method: Its Basis and Fundamentals, 6th ed., Elsevier Butterworth-Heinemann, Oxford 2005.

[4] L.J. Segerlind, Applied Finite Element Analysis, 2nd ed., Wiley, New York 1985.

[5] J.M. Gere, Mechanics of Materials, 6th ed., Brooks/Cole-Thomson Learning, United States of America 2004. 